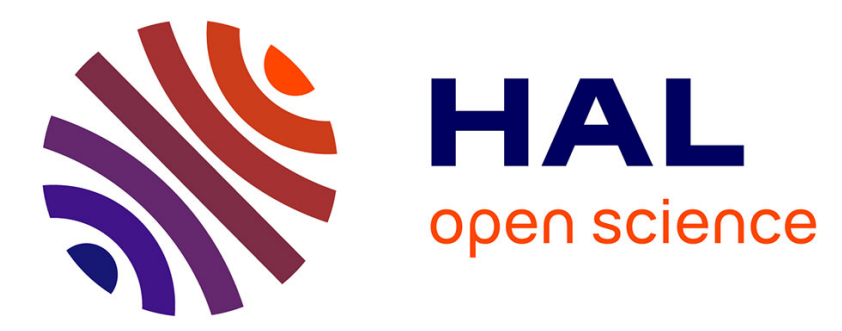

\title{
Chemical profiling of the tuber of Stephania cambodica Gagnep. (Menispermaceae) and analytical control by UHPLC-DAD
}

Chhavarath Dary, Sok-Siya Bun, Gaëtan Herbette, Fathi Mabrouki, Hot Bun, Sothea Kim, Florian P Jabbour, Sovanmoly Hul, Béatrice Baghdikian, Evelyne Ollivier

\section{To cite this version:}

Chhavarath Dary, Sok-Siya Bun, Gaëtan Herbette, Fathi Mabrouki, Hot Bun, et al.. Chemical profiling of the tuber of Stephania cambodica Gagnep. (Menispermaceae) and analytical control by UHPLC-DAD. Natural Product Research, 2016, 31 (7), pp.802-809. 10.1080/14786419.2016.1247077 . hal-01765806

\section{HAL Id: hal-01765806 \\ https://hal-amu.archives-ouvertes.fr/hal-01765806}

Submitted on 19 Apr 2018

HAL is a multi-disciplinary open access archive for the deposit and dissemination of scientific research documents, whether they are published or not. The documents may come from teaching and research institutions in France or abroad, or from public or private research centers.
L'archive ouverte pluridisciplinaire HAL, est destinée au dépôt et à la diffusion de documents scientifiques de niveau recherche, publiés ou non, émanant des établissements d'enseignement et de recherche français ou étrangers, des laboratoires publics ou privés. 
Title: Chemical profiling of the tuber of Stephania cambodica Gagnep.

(Menispermaceae) and analytical control by UHPLC-DAD

Chhavarath Dary $^{\text {abc }}$, Sok-Siya Bun ${ }^{a^{*}}$, Gaëtan Herbette ${ }^{\mathrm{d}}$, Fathi Mabrouki ${ }^{\mathrm{a}}$, Hot

Bun $^{\mathrm{e}}$, Sothea Kim ${ }^{\mathrm{f}}$, Florian Jabbour ${ }^{\mathrm{c}}$, Sovanmoly Hul ${ }^{\mathrm{c}}$, Béatrice Baghdikian ${ }^{\mathrm{a}}$, Evelyne Ollivier ${ }^{\mathrm{a}}$

* Correspondance to: S.S. Bun, 27 Blvd Jean Moulin CS 30064, 13005 Marseille, France.

Email: sok-siya.bun@univ-amu.fr. Tel. +33 491835545

${ }^{a}$ Aix Marseille Univ, UMR-MD3, Laboratory of Pharmacognosy and Ethnopharmacology,

Faculty of Pharmacy, 27 Blvd Jean Moulin CS 30064, 13005 Marseille, France.

${ }^{b}$ University of Health Sciences, Research Unit, 73 Blvd Monivong, Phnom Penh,

Cambodia.

${ }^{c}$ Muséum national d'Histoire naturelle, Institut de Systématique, Évolution, Biodiversité, UMR 7205 ISYEB MNHN/CNRS/UPMC/EPHE, Sorbonne Université, 57 rue Cuvier, CP 39, 75005 Paris, France.

${ }^{d}$ Aix Marseille Univ, Spectropole, FR1739, Service 511, 13397 Marseille, France.

${ }^{e}$ Aix Marseille Univ, Laboratory of Pharmacokinetics and Toxicokinetics, Faculty of Pharmacy, 27 Blvd Jean Moulin CS 30064, 13005 Marseille, France.

${ }^{f}$ University of Health Sciences, Laboratory of Phytochemistry, Faculty of Pharmacy, 73

Blvd Monivong, Phnom Penh, Cambodia. 


\title{
Title: Chemical profiling of the tuber of Stephania cambodica Gagnep. (Menispermaceae) and analytical control by UHPLC-DAD
}

\begin{abstract}
A new aporphine glycoside (1), named "angkorwatine", and eight known alkaloids: oblongine (2), stepharine (3), asimilobine- $\beta$-D-glucopyranoside (4), isocorydine (5), tetrahydropalmatine (THP) (6), jatrorrhizine (7), palmatine (PAL) (8) and roemerine (ROE) (9) were simultaneously isolated from the tuber of Stephania cambodica. The development and validation of UHPLC-DAD method was carried out for the quantification of marker compounds (PAL, ROE, THP) of S. cambodica. In addition to good selectivity and linearity $\left(r^{2}>0.997\right)$, trueness, precision, and accuracy of the method did not exceed the acceptance limit of $\pm 10 \%$ for ROE, THP and $\pm 20 \%$ for PAL. Consequently, this method is able to provide accurate results between $1.39-4.18 \mu \mathrm{g} / \mathrm{mL}, 2.01-30.72 \mu \mathrm{g} / \mathrm{mL}$ and $4.29-64.42 \mu \mathrm{g} / \mathrm{mL}$ for PAL, ROE, and THP, respectively. This study shows that the validated UHPLC method is a rapid, innovative and effective analytical approach to control quality of tubers of $S$. cambodica and to regulate the usage of this plant in traditional medicine.
\end{abstract}

Keywords: Accuracy profile; alkaloid; method validation; palmatine; quantification; roemerine; tetrahydropalmatine.

\section{Introduction}

Stephania cambodica Gagnep. (Menispermaceae) is a woody climber found in mountainous regions in Cambodia and Vietnam. The main characteristic of this species is the absence of leaves during the blooming period. Mature individuals of S. cambodica often have multiple tubers lying on rocks and are interconnected with a woody stem (Figure S1). Known by its Cambodian vernacular name "Komar Pich", the plant tuber has been traditionally used by local people in forms of decoction or hydroethanolic macerate to treat various diseases and symptoms such as anxiety, malaria, fever, wounds, joint pains, fatigue and male sexual dysfunction (Center of Traditional Medicine 2013). In Vietnam, the tuber of S. cambodica is used in combination with other plants for treatment of various diseases such as depression, asthma, hypertension... (Do et al. 1999). Despite its well-established use, few phytochemical studies have been undertaken on S.cambodica (Thanh and Hung 2011; Dinh et al. 2015). Rotundine (l-tetrahydropalmatine) the main alkaloid isolated from $S$. cambodica tuber has 
been shown to be responsible for the inhibition of neurokinine-1 receptor gene expression (Dinh et al. 2015). The presence of rotundine in S. cambodica tuber could justify its traditional use as an anxiolytic remedy in Cambodia since in Vietnam and China, rotundine is used as an anxiolytic and hypnotic drug (Wang and Mantsch 2014). This neuro-sedative activity was also shown in rats and mice (Semwal and Semwal 2015).

Liquid chromatography is widely used for quality control of alkaloids from Stephania species (Bory et al. 2010; Xie et al. 2014; Liu et al. 2016). Ultra-high performance liquid chromatography (UHPLC) method has recently been employed to characterise the alkaloids of Stephania tetrandra S.Moore (Sim et al., 2013). However, the analytical control of the tuber of S. cambodica using these techniques has not yet been documented.

The aims of this study are firstly to characterise chemical constituents of the tuber of S. cambodica, which is the main plant part used in traditional medicine. Secondly, a thorough development and validation of the UHPLC method for the determination of the main metabolites of this plant was performed.

\section{Results and discussion}

A new aporphine glycoside (1,0.5 mg) named "angkorwatine" (Figure 1), and eight known alkaloids namely oblongine (2,0.2 $\mathrm{mg}$ ) (Kato et al. 1995), stepharine (3,0.6 mg) (Thuy et al. 2004), asimilobine- $\beta$-D-glucopyranoside (4, 3.8 mg) (Likhitwitayawuid et al. 1993), isocorydine (5, $0.5 \mathrm{mg}$ ) (Ferreira et al. 2010), tetrahydropalmatine (THP) (6, $1.0 \mathrm{mg}$ ) (Mastranzo et al. 2012), jatrorrhizine (7, $0.1 \mathrm{mg}$ ) (Shi et al. 2015), palmatine (PAL) (8, 0.4 mg) (Shi et al. 2015) and roemerine (ROE) (9, $1.0 \mathrm{mg}$ ) (Thuy et al. 2004) were simultaneously isolated from the hydroethanolic extract of $S$. cambodica by preparative HPLC (Figure S2). The isolation of alkaloids from this species tuber in previous reports involved conventional chromatography (Thanh and Hung 2011).

The alkaloid-type structure of the nine compounds isolated was revealed by the NMR spectra. The NMR data of compounds (2-9) were all in accordance with the literature values.

Angkorwatine (1) was isolated as amorphous powder, and the molecular formula was assigned as $\mathrm{C}_{23} \mathrm{H}_{27} \mathrm{NO}_{8}$ by high-resolution mass spectrum (HR-ESI-MS) $(\mathrm{m} / \mathrm{z} 446.1811$ $[\mathrm{M}+\mathrm{H}]^{+}$, calcd for $\mathrm{C}_{23} \mathrm{H}_{27} \mathrm{NO}_{8}, 446.1809$ ) (Figure S3) and NMR data implying 11 degrees of unsaturation. The ${ }^{13} \mathrm{C}$ NMR data gave a total of 23 separate resonances, including six signals 
assignable to sugar. The ${ }^{1} \mathrm{H}$ NMR spectrum exhibited one methoxy group $\left(\delta_{\mathrm{H}} 3.79\right)$, five aromatic protons $\left(\delta_{\mathrm{H}} 7.12 ; 7.36 ; 7.43 ; 7.47 ; 8.48\right)$, four ethylene protons $\left(\delta_{\mathrm{H}} 3.03 ; 3.27 ; 3.49\right.$; 3.69), one signal of oxymethine proton $\left(\delta_{\mathrm{H}} 4.74\right)$, one signal of methine proton $\left(\delta_{\mathrm{H}} 4.47\right)$, and signals assigned to the sugar moiety with an anomeric proton $\left(\delta_{\mathrm{H}} 4.98, \mathrm{~d}, J=7.8 \mathrm{~Hz}\right)$. The ${ }^{1} \mathrm{H}$ and ${ }^{13} \mathrm{C}$ resonances of $\mathbf{1}$ were typical of 7-oxygenated aporphine glycoside alkaloid. The HMBC crosspeak between H-1' $\left(\delta_{\mathrm{H}} 4.98\right)$ and C-2 $\left(\delta_{\mathrm{C}} 153.1\right)$ and NOESY crosspeak between H-1' $\left(\delta_{\mathrm{H}} 4.98\right)$ and H-3 $\left(\delta_{\mathrm{H}} 7.12\right)$ placed the sugar moiety at C-2 of the 7-oxygenated aporphine. The sugar moiety was identified as $\beta$-D-glucopyranose from the proton signals at $\delta_{\mathrm{H}} 4.98(\mathrm{~d}, J=7.8 \mathrm{~Hz}, \mathrm{H}-1$ '), 3.56 (dd, $J=9.1,7.8 \mathrm{~Hz}, \mathrm{H}-2$ '), 3.48 (brt, $J=9.0 \mathrm{~Hz}, \mathrm{H}-3$ ') 3.40 (dd, J=9.4,9.0 Hz, H-4'), 3.50 (ddd, J=9.4,6.2, 2.0 Hz, H-5'), 3.94 (dd, J=12.1, 2.0 Hz, Ha6'), $3.71\left(\mathrm{dd}, J=12.1,6.2 \mathrm{~Hz}, \mathrm{H}-6^{\prime}\right)$ and from the carbon resonances at $\delta_{\mathrm{C}} 102.5$ (C-1'), 74.9 (C-2'), 78.4 (C-3' and C-5'), 71.5 (C-4'), and 62.3 (C-6') in the ${ }^{13} \mathrm{C}$ NMR spectrum. The HMBC crosspeak between methoxy group H-12 $\left(\delta_{\mathrm{H}} 3.79\right)$ and C-1 $\left(\delta_{\mathrm{C}} 147.5\right)$ and NOESY crosspeak between $\mathrm{H}-12\left(\delta_{\mathrm{H}} 3.79\right)$ and $\mathrm{H}-11\left(\delta_{\mathrm{H}} 8.48\right)$ placed the methoxy group at $\mathrm{C}-1$ of the 7-oxygenated aporphine. The other proton signals were at $\delta_{\mathrm{H}} 3.27(\mathrm{~m}), 3.03$ (brd, 15.8) and $3.69(\mathrm{~m}), 3.49(\mathrm{~m})$ for the four aliphatic protons, which were assigned to $\mathrm{H}-4$ and $\mathrm{H}-5$. The two last signals at $\delta_{\mathrm{H}} 4.77$ (brs) and 4.74 (brs) were assigned to H-6a and H-7. In this particular case, the ${ }^{1} \mathrm{H}$ NMR analysis between 300 and $340 \mathrm{~K}$ did not allow for a coupling constant to be observed between these signals: the two protons $\mathrm{H}-6 \mathrm{a}$ and $\mathrm{H}-7$ appeared as a broad singlet $\left(\mathrm{W}^{1 / 2} \sim 8 \mathrm{~Hz}\right.$ ) which seemed to correspond to a coalescence of a cis $\mathrm{H}-7$ and $\mathrm{H}$ $6 \mathrm{a}(\mathrm{J}=0$-> $3 \mathrm{~Hz})$ (Hocquemiller et al. 1981).

$\mathrm{C}_{23} \mathrm{H}_{27} \mathrm{NO}_{8} .[\alpha]^{25}{ }_{\mathrm{D}}=-72.5^{\circ}\left(\mathrm{CH}_{3} \mathrm{OH}, c\right.$ 0.0008). UV $\left(\mathrm{CH}_{3} \mathrm{OH}\right) \lambda_{\max } 210,272 \mathrm{~nm}$. The NMR spectra and data of angkorwatine are provided in Figure S4-9 and Table S1.

Compounds 1-5 and $\mathbf{9}$ were identified for the first time in the tuber of this species while compounds 4, 6, 8 and 9 were the major alkaloids. The nine compounds isolated belong to five classes of alkaloids, namely aporphine $(\mathbf{1}, \mathbf{3}, \mathbf{4}$, and 9), quinoline (5), benzyltetrahydroisoquinoline (2), protoberberine (7), and tetrahydroprotoberberine $(\mathbf{6}, \mathbf{8})$. As asimilobine- $\beta$-Dglucopyranoside (4) is commercially unavailable, palmatine (8), roemerine (9) and tetrahydropalmatine (6) were selected as analytical markers of $S$. cambodica (Figure 1). 
During the development process, the system suitability test (Table S2) and selectivity of UHPLC method were verified. Concerning the UHPLC conditions, acetonitrile and methanol are frequently preferred to ethanol as the mobile phase in analysis of alkaloids. However, our study shows that ethanol gives a better resolution of the three analytes than methanol and acetonitrile. According to our knowledge, the developed UHPLC method is the first simultaneous determination of palmatine, roemerine and tetrahydropalmatine in the tuber of $S$. cambodica (Figure S2).

This UHPLC method was then validated in terms of analysis of response functions, trueness, precision, accuracy, limits of quantification (LOQ) and detection (LOD) and linearity. The validation parameters are summarised in Table S3. The calibration curves were based on the through-origin linear regression model which was fitted with concentration levels ranging from $1.67-33.20 \mu \mathrm{g} / \mathrm{mL}, 1.54-30.80 \mu \mathrm{g} / \mathrm{mL}$ and $4.24-84.70 \mu \mathrm{g} / \mathrm{mL}$ for PAL, ROE and THP, respectively. Each calibration point was analysed over the course of three consecutive days. Independent validation standards were also prepared by following the same process: five concentration levels ranging from $0.31-4.18 \mu \mathrm{g} / \mathrm{mL}, 2.01-30.72 \mu \mathrm{g} / \mathrm{mL}$ and 4.29-64.42 $\mu \mathrm{g} / \mathrm{mL}$ for PAL, ROE and THP, respectively. Each point was analysed in triplicate over three consecutive days. The coefficients of determination of each-day equation of the regression line were all greater than $R^{2}>0.999$ for reference solutions and test samples. The data have been presented in Table S3. From the results obtained, the concentration of the validation standards were back-calculated to determine the mean relative bias, the relative standard deviation (repeatability and intermediate precision) and the upper and lower $\beta$ expectation tolerance limits at $95 \%$ level. The accuracy profile was built using trueness and intermediate fidelity variance. The acceptance thresholds were set at $\pm 10 \%$ for ROE, THP and at $\pm 20 \%$ for PAL. As indicated in Table S3, trueness expressed in terms of relative bias (\%) was assessed by means of validation standards. RSD values smaller than $5 \%$ illustrated the good trueness of the method. The precision of the method was determined by computing the Relative Standard Deviation (RSDs) for repeatability and time-differentiated intermediate precision at each concentration level of the validation standards. The precision at each concentration level of the validation standards did not exceed $10 \%$ for PAL and 5\% for ROE and THP, as shown in Table S3. The comparable RSDs between repeatability and intermediate fidelity were mainly due to non-significant intergroup variances, validating the 
precision of the developed method. The accuracy of the method was also evaluated taking into account the total error (sum of the systematic and random errors) of the test results. $\beta$ expectation tolerance intervals were determined to investigate the accuracy profile of the method. If $\beta=0.95$, this means that on average, $95 \%$ of the future results are included in the interval. As illustrated in Figure S10 and Table S3, the relative upper and lower $\beta$-expectation tolerance limits (\%) did not exceed the adopted acceptance limits $( \pm 10 \%$ for ROE, THP and $\pm 20 \%$ for PAL). Consequently, the method is able to provide accurate results over the investigated concentration range: $1.39-4.18 \mu \mathrm{g} / \mathrm{mL}, 2.01-30.72 \mu \mathrm{g} / \mathrm{mL}$ and $4.29-64.42$ $\mu \mathrm{g} / \mathrm{mL}$ for PAL, ROE and THP, respectively. As the smallest and highest quantity of the target substance in the sample could be assayed under experimental conditions with welldefined accuracy, the lower and upper LOQ were evaluated by calculating the smallest and highest concentrations. Beyond these points the accuracy limits or $\beta$-expectation tolerance limits would fall outside the acceptance limits. As the accuracy profile was included within the acceptance limits (Figure S10), the first concentration level was considered as the lower LOQ for all molecules studied $(1.39 \mu \mathrm{g} / \mathrm{mL}$ for PAL, $2.01 \mu \mathrm{g} / \mathrm{mL}$ for ROE, and $4.29 \mu \mathrm{g} / \mathrm{mL}$ for THP) and the highest concentration level as the upper LOQ for three alkaloids (4.18 $\mu \mathrm{g} / \mathrm{mL}$ for PAL, $30.72 \mu \mathrm{g} / \mathrm{mL}$ for ROE, and $64.42 \mu \mathrm{g} / \mathrm{mL}$ for THP). As for the limit of detection (LOD), it was estimated using mean intercept of calibration model and the residual variance of the regression. The LODs were evaluated at $0.19 \mu \mathrm{g} / \mathrm{mL}$ for PAL, $0.38 \mu \mathrm{g} / \mathrm{mL}$ for ROE and $2.36 \mu \mathrm{g} / \mathrm{mL}$ for THP. To demonstrate the linearity of the method, a linear regression line through origin was fitted to the estimated or back-calculated concentrations of all the series of validation standards $(N=45)$ as a function of the introduced concentrations. This was done by applying a linear regression model based on the least squares method. The following regression equations were determined: $\mathrm{y}=0.9721 \mathrm{x} \quad\left(r^{2}=0.9975\right), \quad \mathrm{y}=0.9939 \mathrm{x}$ $\left(r^{2}=0.9993\right)$ and $\mathrm{y}=0.9623 \mathrm{x}\left(r^{2}=0.9996\right)$ for PAL, ROE and THP, respectively (Table S3).

The developed and validated method was applied to quantify alkaloid content in different samples of S. cambodica (Table S4). Subsequently, no difference in alkaloid content in tubers collected in the two successive years was observed. The results suggested that the collection time may not have influenced the alkaloid content in this species. The content of PAL, ROE and THP in stem was comparative to those of tubers. As the stem is a renewable part, it could 
potentially be a good alternative to tubers in traditional use. Also, the use of the stem assists in reducing over-exploitation of $S$. cambodica and hence preserving this species.

\section{Experimental}

\subsection{Plant material}

The plant collection for research was approved by the Ministry of Health in Cambodia. Vegetal material was collected in two successive years from the same individual plant in Preah Vihear in Cambodia (14.223143 N-104.980178 E) (Figure S1). It was authenticated by Dr. Sovanmoly Hul. Vouchers were then deposited at Paris Herbarium (France).

\subsection{Reagents and materials}

Ethanol, methanol and formic acid of HPLC Ultra-Gradient grade were purchased from Carlo Erba (Val de Reuil, France). Ultrapure water (18.2 M $\Omega$ ) for HPLC analysis was obtained from a Milli-Q Reference A+ system (Millipore, CO., Bedford, MA, USA). Palmatine, roemerine and tetrahydropalmatine were purchased from Sigma-Aldrich (Saint Quentin Fallavier, France), Ambinter (Orléans, France) and Phytolab (Vestenbergsgreuth, Germany), respectively.

\subsection{Phytochemical study}

\subsubsection{Preparative HPLC isolation}

Dried powder of $S$. cambodica tuber $(0.5 \mathrm{~g})$ was extracted with $10 \mathrm{~mL}$ of ethanol $50 \%(\mathrm{v} / \mathrm{v})$ for $15 \mathrm{~min}$ in a microwave (CEM Corporation Matthews, NC, USA). This extractive protocol was developed in a previous study (Desgrouas et al. 2014). The dried extract (50 mg) was dissolved in a $2.5 \mathrm{~mL}$ mixture of formic acid $0.1 \%(\mathrm{v} / \mathrm{v})$ methanol (70:30, v/v). The isolation of the compounds was carried out using a Gilson PLC 2020® preparative chromatograph with a DAD detector (LT350026, Gilson inc., USA). The separation and purification of the constituents were performed on the Luna C18 column $(10 \mu \mathrm{m}, 150 \times 4.6 \mathrm{~mm}-$ Phenomenex $)$. A solvent system consisting of formic acid $0.1 \%$ (v/v) (A) and methanol (B) was used as the mobile phase in gradient mode. The eluting program was optimised as follows: linear gradient from $10 \%$ to $80 \% \mathrm{~B}(0-60 \mathrm{~min})$. The flow rate was $12 \mathrm{~mL} / \mathrm{min}$ with monitoring at $272 \mathrm{~nm}$.

\subsubsection{Identification of the isolated compounds}

Structural elucidation of isolated compounds was based on spectroscopic experiments: 1D and 2D NMR, ESIMS/HRESIMS and by comparison of the spectral and chemical data with 
literature. ${ }^{1} \mathrm{H}$ and ${ }^{13} \mathrm{C}$ NMR spectra were measured with a $600 \mathrm{MHz}$ Avance III spectrometer

(Bruker) $\left({ }^{1} \mathrm{H}, 600 \mathrm{MHz} ;{ }^{13} \mathrm{C}, 150 \mathrm{MHz}\right)$, equipped with a $5 \mathrm{~mm} \mathrm{BBFO}{ }^{+}$probe. Spectra were recorded with a 2-mm NMR capillary tube in $80 \mu \mathrm{L}$ of $99.96 \% \mathrm{CD}_{3} \mathrm{OD}$ solvent $\left(\delta^{1} \mathrm{H} 3.31\right.$ $\left.\mathrm{ppm}-\delta{ }^{13} \mathrm{C} 49: 00 \mathrm{ppm}\right)$ at $300 \mathrm{~K}$. The ${ }^{1} \mathrm{H}(600 \mathrm{MHz})$ and ${ }^{13} \mathrm{C}$ NMR $(150 \mathrm{MHz})$ data were reported in ppm downfield from tetramethylsilane. Coupling constants were expressed in $\mathrm{Hz}$ where s stands for singlet, $\mathrm{d}$ for doublet, $\mathrm{t}$ for triplet, $\mathrm{q}$ for quartet, $\mathrm{m}$ for multiplet and $\mathrm{br}$ for broad. Hydrogen connectivity $\left(\mathrm{C}, \mathrm{CH}, \mathrm{CH}_{2}, \mathrm{CH}_{3}\right)$ information was obtained from edited HSQC and/or DEPTQ-135 experiments. Proton and carbon peak assignments were based on 2D NMR analyses. ESIMS / HRESIMS analyses were measured with a SYNAPT G2 HDMS mass spectrometer (Waters). Accurate mass measurements were performed in triplicate with two internal calibrations. The direct sample introduction was performed at a $5 \mu \mathrm{L} / \mathrm{min}$ flow rate. Optical rotations were recorded on a Anton Paar MCP200 589 nm Polarimeter equipped with a sodium lamp $\left(\mathrm{CH}_{3} \mathrm{OH}, c\right.$ in $\left.\mathrm{g} / \mathrm{mL}\right)$.

\subsection{UHPLC analysis}

The UHPLC apparatus used for the analysis of PAL, ROE, and THP were an Agilent Infinity 1290 liquid chromatography system equipped with a binary pump solvent delivery system and photodiode array detector (Agilent technologies Inc., Germany). Chromatographic separation was achieved on a Zorbax Eclipse Plus RRHD-C18 column $(50 \times 2.1 \mathrm{~mm}, 1.8 \mu \mathrm{m}$, Agilent, Germany), operated at $30^{\circ} \mathrm{C}$. The mobile phase consisted of a gradient elution of formic acid $0.1 \%(\mathrm{v} / \mathrm{v})$ (solvent A) and ethanol (solvent B). The gradient program was: $0-1 \mathrm{~min}$ at $5 \%$ of $\mathrm{B}, 1-7 \mathrm{~min}$ from 5 to $42 \%$ of B with $3 \mathrm{~min}$ of post-time at a flow rate of $0.35 \mathrm{~mL} / \mathrm{min}$. The injected volume was $2 \mu \mathrm{L}$. UV detection wavelengths were $280 \mathrm{~nm}$ for THP and $272 \mathrm{~nm}$ for PAL and ROE. The system suitability test and selectivity of the method were carried out following FDA (1994) and ICH guidelines (2005).

\subsection{Method validation}

The validation strategy was based on the recommendations of the "Société Française des Sciences et Techniques Pharmaceutiques" (SFSTP) (Bellenot et al. 2015). In order to validate the analytical method, two kinds of samples were prepared independently. The concentrations of calibration standards (THP, PAL and ROE) are presented in Table S3. The desired concentrations of the validation standard was obtained by ultrasonication of different weight 
of powdered tuber for $10 \mathrm{~min}$ in $10 \mathrm{~mL}$ of ethanol $50 \%(\mathrm{v} / \mathrm{v})$. One $\mathrm{mL}$ of the filtrate was diluted in $20 \mathrm{~mL}$ of ethanol $50 \%$ prior to analysis (Table S3).

\section{Conclusions}

Nine alkaloids were simultaneously isolated from the hydroethanolic extract of the tuber of Stephania cambodica. A new isolated glycoalkaloid was named angkorwatine. This particular study suggests that the validated method for the quantification of palmatine, roemerine and tetrahydropalmatine is a rapid, innovative and effective analytical approach to control the quality of the tuber of $S$. cambodica and regulate its use in traditional medicine.

\section{Supplementary material}

The underlying research materials for this article is available online, alongside Figure $\mathrm{S} 1-\mathrm{S} 10$.

\section{Disclosure statement}

Authors declare no conflict of interest in this work.

\section{Funding}

The research was supported by French government scholarships.

\section{References}

Bellenot D, Barrau E, Chanel I, Dufat H, Brum M, Abbe P, Alet P, Baghdikian B, Lugez M, Maciuk A, Portier G, Romerales C, Saperas O, Seigneuret JM, Soussain R. 2015. Issues of an analytical procedure development for the assay of constituents in herbal medicinal products IV. Recommendation for development and validation. STP Pharma Prat. 25:235-270.

Bory S, Bun SS, Baghdikian B, Mabrouki F, Cheng SK, Elias R, Bun H, Ollivier E. 2010. Simultaneous HPLC determination of three bioactive alkaloids in the Asian medicinal plant Stephania rotunda. Nat Prod Commun. 5:877-882.

Center of Traditional Medicine. 2013. Cambodian medicinal plants. Part 1. Phnom Penh: Ministry of Health. 
Desgrouas C, Baghdikian B, Mabrouki F, Bory S, Taudon N, Parzy D, Ollivier E. 2014.

Rapid and green extraction, assisted by microwave and ultrasound of cepharanthine from Stephania rotunda Lour. Sep Purif Technol. 123:9-14.

Dinh LD, Hong N, Pham T, Thi NM. 2015. Interaction of Vietnamese Medicinal Plant Extracts with Recombinantly Expressed Human Neurokinin-1 Receptor. Planta Medica Lett. 2:42-47.

Do H, Nguyen V, Nguyen G. 1999. Selected Medicinal Plants in Vietnam. Hanoi: Vietnam Science and Technology Publishing House.

Ferreira MLR, de Pascoli IC, Nascimento IR, Zukerman-Schpector J, Lopes LMX. 2010. Aporphine and bisaporphine alkaloids from Aristolochia lagesiana var. intermedia. Phytochemistry. 71:469-478.

Hocquemiller R, Rasamizafy S, Moretti C, Jacquemin H, Cavé A. 1981. Anaxagoreine, a new aporphine alkaloid, isolated from two species of the genus Anaxagorea. Planta Med. 41:48-50.

Kato A, Moriyasu M, Ichimaru M, Nishiyama Y. 1995. Examination of Alkaloidal Constituents of Zanthoxylum usambarense by a Combination of Ion-pair Extraction and Ion-pair Chromatography Using Sodium Perchlorate. Phytochem Anal. 6:89-95.

Likhitwitayawuid K, Angerhofer C, Chai H, Pezzutot JM, Cordell GA. 1993. Cytotoxic and antimalarial alkaloids from the tubers of Stephania pierrei. J Nat Prod. 56:1468-1478.

Liu Y, Xie D, Kang Y, Wang Y. 2016. Microwave-Assisted Extraction Followed by SolidPhase Extraction for the Chromatographic Analysis of Alkaloids in Stephania cepharantha. J Chromatogr Sci. 54:670-676.

Mastranzo VM, Olivares Romero JL, Yuste F, Ortiz B, Sánchez-Obregón R, García Ruano JL. 2012. Asymmetric synthesis of (S)-(-)-tetrahydropalmatine and (S)-(-)-canadine via a sulfinyl-directed Pictet-Spengler cyclization. Tetrahedron. 68:1266-1271.

Semwal DK, Semwal RB. 2015. Efficacy and safety of Stephania glabra: An alkaloid-rich traditional medicinal plant. Nat Prod Res. 29: 396-410.

Shi X, Li X, Zou M. 2015. Chemical Constituents and Biological Activities of Stephania yunnanensis H.S. Lo. Biomed Res. 26:715-720. 
Sim HJ, Kim JH, Lee KR, Hong J. 2013. Simultaneous determination of structurally diverse compounds in different fangchi species by UHPLC-DAD and UHPLC-ESI-MS/MS. Molecules. 18:5235-5250.

Thanh MC, Hung T. 2011. Two protoberberine alkaloids isolated from tuber of Stephania cambodica Gagnep. (Menispermaceae). Y Hoc TP Ho Chi Minh. 15:565-569.

Thuy TT, Sung T Van, Franke K, Wessjohann L. 2004. Aporphine and protoaporphine alkaloids from Stephania rotunda. J Chem. 43:619-623.

Wang JB, Mantsch JR. 2014. Treatment of Cocaine Addiction. Futur Med Chem. 4.

Xie DT, Wang YQ, Kang Y, Hu QF, Su NY, Huang JM, Che CT, Guo JX. 2014. Microwave-assisted extraction of bioactive alkaloids from Stephania sinica. Sep Purif Technol. 130:173-181. 


\section{Figure caption}

Figure 1. Structures of angkorwatine (1), tetrahydropalmatine $(\mathbf{6})$, palmatine $(\mathbf{8})$, roemerine (9)

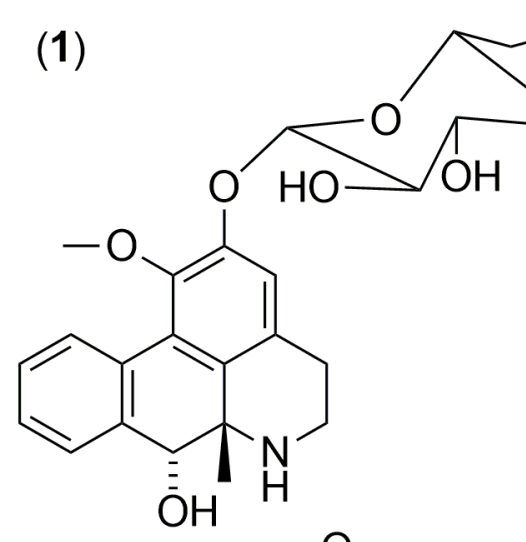<smiles>OCO</smiles>

(6)<smiles>COc1cc2c(cc1OC)-c1cc3ccc(OC)c(OC)c3c[n+]1CC2</smiles><smiles>CN1CCc2cc3c(c4c2[C@@H]1Cc1ccccc1-4)OCO3</smiles> 